\title{
Description and Comparison of Eggs and Yolk Sac Larvae of Greenland Cod (Gadus ogac), Atlantic Cod (Gadus morhua) and Arctic Cod (Boreogadus saida) from West Greenland Waters
}

\author{
O. G. N. Andersen* \\ The National Forest and Nature Agency, Haraldsgade 53 \\ DK-2100 Copenhagen $\varnothing$, Denmark \\ J. R. Nielsen* \\ Danish Institute for Fisheries and Marine Research, Charlottenlund Castle \\ DK-2920 Charlottenlund, Denmark \\ and \\ E. L. B. Smidt* \\ Greenland Fisheries Research Institute, Tagensvej 135 \\ DK-2200 Copenhagen N, Denmark
}

\begin{abstract}
Laboratory reared eggs and yolk sac larvae of Greenland cod (Gadus ogac) from West Greenland are described and compared to wild-caught larvae from West Greenland presumed to be G. ogac, to wild-caught larvae of Atlantic cod (Gadus morhua) from West Greenland waters and in the literature, to larvae of Arctic cod (Boreogadus saida) in the literature and wild-caught in West Greenland waters and to a literature description of larvae of toothed cod (Arctogadus borisovi). The almost total absence of external pre-anal pigmentation with none dorsally in late stage embryos and yolk sac larvae of $\mathrm{G}$. ogac up to $5.2 \mathrm{~mm}$ notochord length (NL) distinguishes them from the other species, where extensive external pre-anal pigmentation is always present, at least dorsally. Also, a larger maximum yolk sac larval size of at least $5.2 \mathrm{~mm} \mathrm{NL}$ (based on reared specimens) compared to a maximum of 4.0-4.5 $\mathrm{mm} \mathrm{NL}$ and post-anal length/total length ratios of $0.55-0.59$ compared to 0.51 respectively in $G$. ogac and $G$. morhua distinguish these species. Concerning the post-anal pairs of dorsal and ventral pigment bars and ventral and dorsal caudal melanophores posterior to these, in G. ogac the first dorsal bar is usually shorter than the ventral bar, while the second dorsal bar is usually the longer of the pair, and there are 2-6 ventral and 0-1 dorsal melanophores. In G. morhua the ventral bars are the wider and there are 1-2 ventral melanophores. In $B$. saida both of the dorsal pigment bars are wider than the ventral ones, and there are 0-1 ventral and 0-2 dorsal melanophores. Three 6-12 mm NL G. morhua larvae from West Greenland have a 24-38\% greater horizontal eye width than larvae of similar sizes from boreal North Atlantic waters.
\end{abstract}

Keywords: $\quad$ Arctic cod, Atlantic cod, eggs, Greenland cod, larvae, West Greenland

\section{Introduction}

Apart from some specimens of Arctic cod (Boreogadus saida (Lepechin, 1774)), all gadid larvae from plankton surveys carried out in July 1925-39 and 1946-85 in West Greenland waters by the Greenland Fisheries Research Institute have been labelled Gadus morhua Linnaeus, 1758, Atlantic cod. Some of these larvae may be Greenland cod (G. ogac, Richardson, 1836) the eggs and larvae of which hitherto have not been described (Nielsen and Morin, 1993). Off West Greenland G. ogac spawns in February-May with a peak in February-March (Jensen, 1926; 1948). This period coincides with recent maximum landings of roe from this species in March in the Godthåb/Nuuk area in West Greenland (Nielsen, 1992). In West Greenland waters G. morhua spawns in February-July with a distinct peak in April (Jensen and Hansen, 1931; Smidt, 1979). Gadus ogac is mainly distributed in

* Authorship equal 
coastal and inshore areas, and its eggs are believed to be demersal (Svetovidov, 1948; Hansen, 1949). Gadus morhua occurs and spawns in both inshore, coastal and offshore areas, and has pelagic eggs (Svetovidov, 1948; Hansen, 1949). Other gadids, the known distributions of which overlap those of both $G$. ogac and $G$. morhua in West Greenland waters, are Arctic cod (B. saida), saithe (Pollachius virens (Linnaeus, 1758)), haddock (Melanogrammus aeglefinus (Linnaeus, 1758)), and two high arctic species, toothed cod (Arctogadus borisovi (Drjagin, 1932)) and polar cod (A. glacialis (Peters, 1874)). Characters distinguishing eggs with late embryos as well as the larvae of $B$. saida from those of $G$. morhua are thoroughly described in Schmidt (1905) and Russell (1976). Pollachius virens and $M$. aeglefinus have neither been reported spawning nor in spawning condition in West Greenland waters (Sv. Aa. Horsted, Greenland Fisheries Research Institute, Copenhagen, pers. comm.). Eggs carrying late stage embryos showing larval pigmentation, as well as larvae up to 10$15 \mathrm{~mm}$ long of the three species $B$. saida, $P$. virens and $M$. aeglefinus, are usually easy to identify and distinguish (Russell, 1976). The main distribution and possible areas of spawning of $A$. borisovi and A. glacialis in West Greenland is north of Disko Bay. Only $A$. borisovi has been found further south, once in Disko Bay and once in South Greenland (Nielsen and Jensen, 1967; Jensen, Greenland Fisheries Research Institute, pers. comm.). The larvae of $A$. borisovi have been partly described (Zviagina, 1961), whereas neither eggs nor larvae of $A$. glacialis are known (Dunn and Vinter, 1984). However, flexion larvae, in which the caudal fin has developed, can be assigned either to the genus Arctogadus or to G. ogac, according to the structure of this fin (Dunn and Vinter, 1984). Therefore, G. ogac is the species most likely to have been taken for G. morhua, and perhaps also for B. saida, in spring samples from coastal and inshore areas in the central and southern waters of West Greenland in 1925-85. Possible misidentification may also present a problem, when analyzing plankton samples from eastern Canadian coastal and inshore waters, for example in the Gulf of St. Lawrence, along the Newfoundland and Labrador coast and in Hudson Strait, where the two species coexist and spawn (Hunter et al., 1984; Scott and Scott, 1988). Based on rearings of $G$. ogac eggs and larvae from known adults from West Greenland waters in 1959 and 1960, the ontogeny of this species is described and compared to that of $G$. morhua and B. saida.

\section{Materials and Methods}

Dry fertilization of $G$. ogac from off Godthåb/ Nuuk, West Greenland was performed on 17 March
1959, 29 February and 14 March 1960 and 18 February 1961 by J. Kreutzmann at the Greenland Fisheries Research Laboratory, Godthåb/Nuuk. Running roe and sperm from adult specimens which had been carefully wiped dry were mixed in a jar. After stirring, seawater was added and the eggs were poured into shallow aquaria containing running seawater from the nearby subtidal zone, maintaining a depth of 6-7 cm. The fertilized eggs immediately settled on the bottom of the aquaria. At a mean temperature of $2^{\circ} \mathrm{C}$, (from $0.5^{\circ}$ to at times $8^{\circ} \mathrm{C}$ due to tide induced halts in water renewal), the eggs hatched after 24 to 35 days. The hatched larvae, unfed except by what might have been present in the running seawater, died after 6 to 8 days.

In 1959, eggs were sampled 22 and 32 days after fertilization, and some yolk sac larvae of unknown hatching dates, were sampled 35 and 36 days after fertilization. In 1960, some larvae which had hatched after 27 days were sampled 8 days later. All were fixed in $4 \%$ formaldehyde neutralized with borax and transferred to $80 \%$ ethanol, after which they were drawn using a dissecting microscope equipped with a "camera lucida". Pigmentation of these embryos and larvae was fully intact.

In 50 to $0 \mathrm{~m}$ vertical plankton tows a $\mathrm{G}$. ogac yolk sac larva was caught on 7 June, and a $B$. saida larva was caught on 15 May 1973 in Disko Bay off Godhavn (bottom depth c. $100 \mathrm{~m}$ ), and two G. ogac larvae were caught in Kangikerdlak in the inner part of Disko Fjord (bottom depth ca. $60 \mathrm{~m}$ ) on 17 June 1974 (Andersen, 1981). These larvae were fixed in $3 \%$ formaldehyde neutralized with borax. The $B$. saida larva was measured and a drawing made immediately while pigmentation was intact. It was drawn again in 1977 along with the other larvae, after pigmentation had begun to deteriorate. Two planktonic G. morhua larvae (out of 267 larvae) caught in $30 \mathrm{~min}$. 100 to $50 \mathrm{~m}$ oblique wire tows on 17 June 1957 off Godthåb/Nuuk, and a larva caught in a similar 400 to $0 \mathrm{~m}$ wire tow on 11 July 1959 south of Godthåb/Nuuk, were also fixed and drawn immediately or in the case of the latter larva 3 years later in 1962.

The reared $G$. ogac larvae were compared to the wild-caught West Greenland larvae and, just as the West Greenland G. morhua larvae, also to the literature (M'Intosh and Masterman, 1897; Ehrenbaum, 1905-1909; Schmidt, 1905; Murray and Hjort, 1912; Zviagina, 1961; Russell, 1976; Fahay, 1983; Dunn and Vinter, 1984).

Descriptions and comparisons of pigmentation were based on the drawings, where those of $G$. morhua and $B$. saida were the only existing draw- 
ings of West Greenland material, and on illustrations and descriptions from literature on these and other species. In the illustrated larvae of G. ogac and $B$. saida, all of the samples of which are kept at the Zoological Museum, University of Copenhagen, the pigmentation was no longer intact, and the samples of $G$. morhua larvae no longer exist. Morphometric measurements (all made from drawings) used for comparison are shown in Fig. 1 and listed in Table 1, and pigmentation characteristics are listed in Table 2.

\section{Results}

Gadus ogac eggs and larvae reared in 1959 and drawn when pigmentation was fully intact (Fig. 2-4)

Sampled eggs of $G$. ogac, fertilized on 17 March 1959, are presented in Fig. 2. Eggs a and b, preserved 22 days after fertilization, both measure $1.13 \mathrm{~mm}$ in diameter, while eggs $\mathrm{c}$ and $\mathrm{d}$, preserved 32 days after fertilization, measure $1.17 \mathrm{~mm}$ in diameter. The eggs are transparent and spherical with no sign of ornamentation of the chorion. The yolk sac is unsegmented and without oil globules. The perivitelline space narrows from ca. $0.1 \mathrm{~mm}$ in a and $b$ to $0.0 \mathrm{~mm}$ in $\mathrm{c}$ and $\mathrm{d}$, where the entire length of the embryos touch the chorion.

Of the two 22 days old embryos, one (a) is less advanced. It has minute melanophores scattered and evenly spaced in the occipital region and laterally above the rudimentary pectoral fin. A middorsal row of melanophores runs ca. 1/3 of the way from above the pectoral fin to the caudal tip. Irregular and semi-continual dorso-lateral and dorsoventral rows of melanophores run from the pecto-

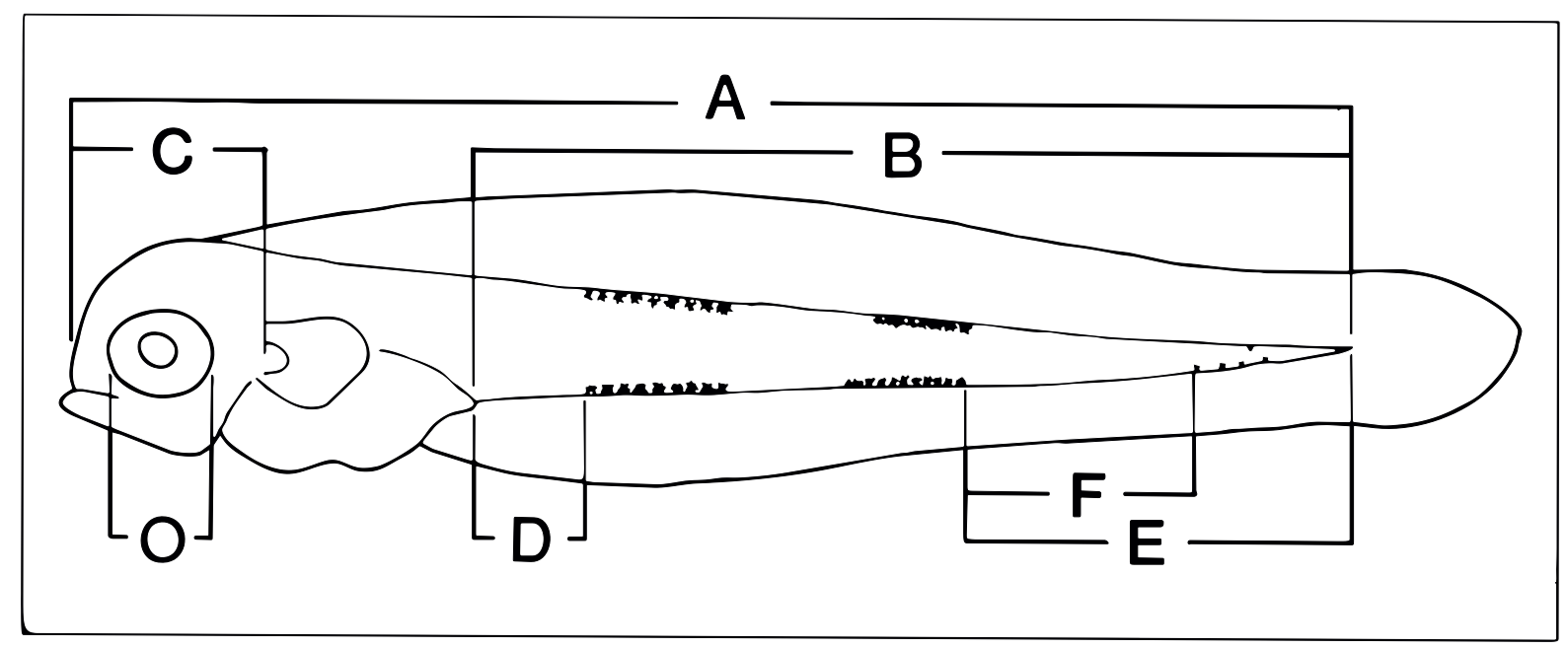

Fig. 1. A schematic gadid larva showing morphometric measurements. Letters refer to length measurements in Table 1.

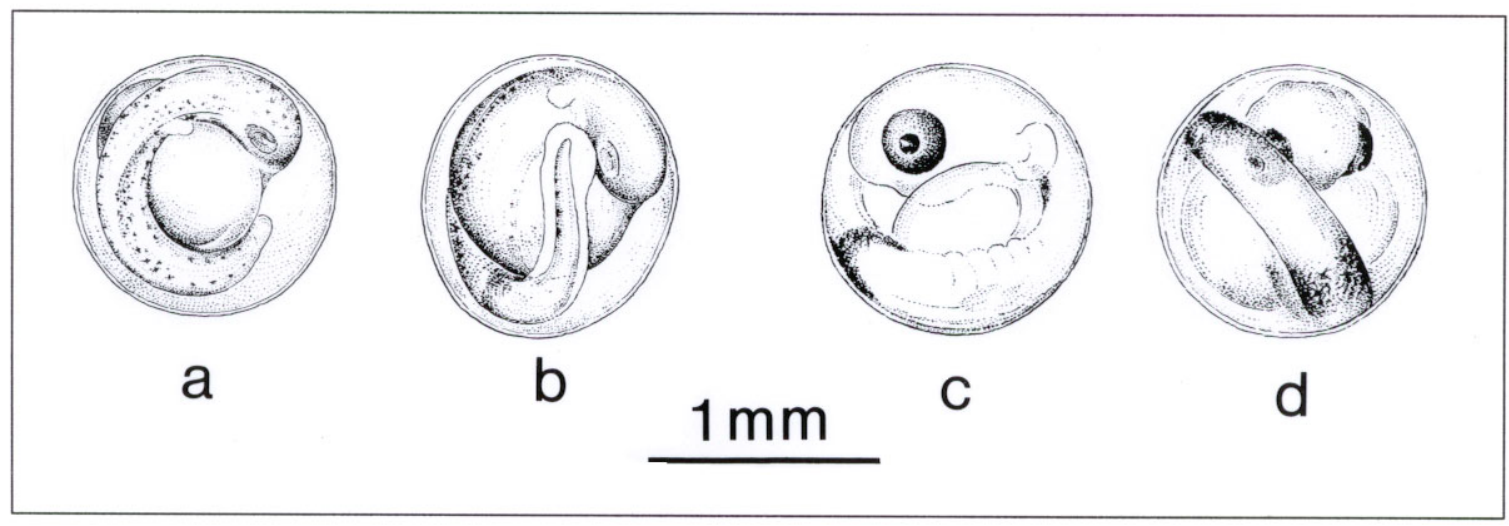

Fig. 2. Reared eggs of Gadus ogac fertilized on 17 March 1959: (a and b) 22 days old measuring 1.13 $\mathrm{mm}$; (c and $\mathbf{d}$ ) 32 days old measuring $1.17 \mathrm{~mm}$ (illustrated by P. H. Winther). 
TABLE 1. Morphometric measurements (in mm) of larvae of Gadus ogac, G. morhua, Boreogadus saida and Arctogadus borisovi (see Fig. 1) listed by lengths $A$ and for tails by $B$ or $E$. $A$ = notochord length (NL) from tip of snout including upper jaw to tip of notochord; $B=$ post-anal length from posterior tip of gut or anus to tip of notochord; $C$ = pre-pectoral fin length from tip of snout including upper jaw to the most anterior margin of base of pectoral fin; $D=$ post-anal distance to anterior margin of ventral part of first caudal pigment band or ventral pigment bar, when the band has split into bars; $E$ = distance from posterior margin of ventral part of second pigment band or ventral pigment bar to tip of notochord; $F=$ distance from posterior margin of ventral part of second pigment band or pigment bar to first medio-ventral caudal melanophore; $\mathrm{O}=$ horizontal eye width; $\mathrm{Xa-t}=$ specimens not illustrated; $\mathrm{Y}=$ yolk sac larva.

\begin{tabular}{|c|c|c|c|c|c|c|c|c|c|c|c|}
\hline Fig. No. & A & $B$ & $\mathrm{~B} / \mathrm{A}$ & C & $\mathrm{C} / \mathrm{A}$ & $\mathrm{D}$ & $E$ & $E / A$ & $\mathrm{~F}$ & $\mathrm{O}$ & $\mathrm{O} / \mathrm{A}$ \\
\hline \multicolumn{12}{|c|}{ Gadus ogac } \\
\hline $4 b-Y$ & & & & & & & 0.82 & & 0.22 & & \\
\hline 3a-Y & 4.01 & 2.30 & 0.57 & 0.62 & 0.15 & 0.14 & 0.86 & 0.21 & 0.09 & 0.27 & 0.067 \\
\hline $3 b-Y$ & 4.32 & 2.55 & 0.59 & 0.70 & 0.16 & 0.16 & 0.86 & 0.19 & 0.05 & 0.27 & 0.062 \\
\hline $3 c-Y$ & 4.35 & 2.42 & 0.55 & 0.68 & 0.15 & 0.08 & 0.86 & 0.19 & 0.04 & 0.35 & 0.083 \\
\hline $4 c-Y$ & & & & & & & 0.93 & & 0.39 & & \\
\hline $4 a-Y$ & & & & & & & 0.98 & & 0.35 & & \\
\hline $5 a-Y$ & 4.47 & 2.62 & 0.59 & 0.58 & 0.13 & 0.33 & 0.74 & 0.16 & 0.28 & 0.31 & 0.069 \\
\hline $7 a-Y$ & 4.72 & 2.81 & 0.59 & & & 0.36 & 0.96 & 0.20 & 0.41 & 0.30 & 0.063 \\
\hline $7 c-Y$ & 4.89 & & & 0.81 & 0.16 & & & & & 0.31 & 0.063 \\
\hline $7 b-Y$ & 4.93 & 2.95 & 0.59 & & & 0.27 & 1.29 & 0.26 & 1.03 & 0.31 & 0.063 \\
\hline$X a-Y$ & & 2.98 & & & & 0.25 & 0.87 & & 0.22 & & \\
\hline$X b-Y$ & & 3.02 & & & & 0.24 & 0.76 & & 0.24 & & \\
\hline$X_{C}-Y$ & & 3.05 & & & & 0.29 & 0.89 & & 0.44 & & \\
\hline $6 a-Y$ & & 3.06 & & & & 0.29 & 0.97 & & 0.54 & & \\
\hline $5 b-Y$ & 5.22 & 3.10 & 0.59 & 0.72 & 0.14 & 0.26 & 1.09 & 0.20 & 0.63 & 0.35 & 0.067 \\
\hline$X d-Y$ & & 3.13 & & & & 0.22 & 0.97 & & 0.37 & & \\
\hline $6 c-Y$ & & 3.14 & & & & 0.22 & 0.76 & & 0.27 & & \\
\hline$X e-Y$ & & 3.17 & & & & 0.33 & 1.05 & & 0.68 & & \\
\hline $6 b-Y$ & & 3.21 & & & & 0.30 & 0.97 & & 0.29 & & \\
\hline \multicolumn{12}{|c|}{ Gadus morhua } \\
\hline$X f-Y^{3}$ & 3.00 & 1.53 & 0.51 & & & 0.22 & 0.60 & 0.20 & 0.40 & 0.19 & 0.063 \\
\hline$X g-Y^{2}$ & 4.00 & 2.06 & 0.51 & 0.57 & 0.14 & 0.25 & 0.73 & 0.18 & 0.38 & 0.26 & 0.065 \\
\hline $\mathrm{Xh}^{4}$ & 4.50 & 2.28 & 0.50 & 0.98 & 0.21 & 0.00 & 0.85 & 0.18 & 0.56 & 0.35 & 0.077 \\
\hline$X i^{3}$ & 5.00 & 2.79 & 0.55 & 1.00 & 0.20 & 0.21 & 1.11 & 0.22 & 0.64 & 0.36 & 0.072 \\
\hline$x j^{3}$ & 6.00 & 3.56 & 0.59 & 1.47 & 0.24 & 0.36 & 1.46 & 0.24 & 0.80 & 0.44 & 0.073 \\
\hline $8 a$ & 6.28 & 3.48 & 0.55 & 1,52 & 0.24 & 0.04 & 1.16 & 0.18 & 0.28 & 0.56 & 0.089 \\
\hline $8 b$ & 7.94 & 4.10 & 0.51 & 1.96 & 0.24 & 0.00 & 1.38 & 0.17 & 0.24 & 0.72 & 0.091 \\
\hline $\mathrm{Xk}^{3}$ & 8.00 & 4.31 & 0.53 & 2.16 & 0.27 & 0.00 & 1.84 & 0.23 & 1.03 & 0.54 & 0.068 \\
\hline 9 & 11.78 & 5.86 & 0.49 & 3.09 & 0.26 & 0.21 & 2.10 & 0.17 & & 1.20 & 0.102 \\
\hline$X I^{3}$ & 12.50 & 6.61 & 0.52 & 3.13 & 0.25 & 0.43 & 2.03 & 0.16 & 1.89 & 0.94 & 0.075 \\
\hline \multicolumn{12}{|c|}{ Boreogadus saida } \\
\hline $10 b-Y$ & 5.90 & 3.72 & 0.63 & & & 0.79 & 0.73 & 0.12 & & 0.43 & 0.073 \\
\hline$X m-Y^{1}$ & 6.30 & 4.12 & 0.65 & 0.96 & 0.15 & 0.50 & 1.17 & 0.18 & & 0.32 & 0.051 \\
\hline $\mathrm{Xn}^{3}$ & 6.50 & 4.29 & 0.66 & 0.86 & 0.13 & 0.36 & 1.08 & 0.17 & & 0.38 & 0.058 \\
\hline $10 a-Y$ & 6.60 & 4.31 & 0.65 & 0.90 & 0.14 & 0.95 & 1.21 & 0.18 & & 0.45 & 0.068 \\
\hline $\mathrm{Xo}^{1}$ & 7.30 & 4.51 & 0.61 & 1.49 & 0.20 & 0.39 & 1.30 & 0.17 & & 0.59 & 0.081 \\
\hline$x p^{3}$ & 8.00 & 5.24 & 0.66 & 1.51 & 0.19 & 0.65 & 1.41 & 0.18 & 1.03 & 0.52 & 0.066 \\
\hline $\mathrm{Xq}^{1}$ & 10.10 & 5.28 & 0.52 & 2.80 & 0.27 & 0.40 & 0.95 & 0.09 & & 0.90 & 0.089 \\
\hline$X r^{3}$ & 11.00 & 6.71 & 0.61 & 2.54 & 0.23 & 0.65 & 1.56 & 0.14 & & 0.82 & 0.075 \\
\hline \multicolumn{12}{|c|}{ Arctogadus borisovi } \\
\hline$X s^{5}$ & $<11.90$ & & 0.58 & & 0.26 & 0.00 & & 0.11 & & & 0.080 \\
\hline$x t^{5}$ & 11.90 & 6.91 & 0.58 & 2.25 & 0.19 & 0.00 & 1.45 & 0.12 & & 0.74 & 0.062 \\
\hline
\end{tabular}

${ }^{1}=$ Dunn and Vinter, 1984; ${ }^{2}=$ M'Intosh and Masterman, 1897; ${ }^{3}=$ Russell, 1976; ${ }^{4}=$ Schmidt, $1905 ;{ }^{5}=$ Zviagina, 1961. 
TABLE 2. Larvae of Gadus ogac, G. morhua, Boreogadus saida and Arctogadus borisovi listed as in Table 1 with some pigmentation characteristics used for comparisons. P1 = width of dorsal part (D) relative to ventral part (V) of first post-anal pigment band, or dorsal bar relative to ventral bar, when the band has split; P2 as in P1 for second pigment band or pair of pigment bars; $\mathrm{P} 3$ = number of medio-ventral caudal melanophores; P4 = number of medio-dorsal caudal melanophores; P5 = dorsal (D), ventral (V) or no (-) bars having fused along the midline; $\mathrm{P} 6=$ occipital pigments present $(+)$ or absent $(-)$; $\mathrm{P} 7=$ ventral abdominal pigments present $(+)$ or absent $(-)$; Xa-t = specimens not illustrated; $\mathrm{Y}=$ yolk sac larvae.

\begin{tabular}{|c|c|c|c|c|c|c|c|c|}
\hline Fig. No. & A & P1 & P2 & P3 & P4 & P5 & P6 & P7 \\
\hline \multicolumn{9}{|c|}{ Gadus ogac } \\
\hline $4 b-Y$ & & & $D>V$ & 2 & 0 & - & & \\
\hline $3 a-Y$ & 4.01 & $D<V$ & $\mathrm{D}=\mathrm{V}$ & 6 & 0 & - & - & - \\
\hline $3 b-Y$ & 4.32 & $\mathrm{D}>\mathrm{V}$ & $\mathrm{D}>\mathrm{V}$ & 5 & 0 & - & - & - \\
\hline $3 c-Y$ & 4.35 & $\mathrm{D}=\mathrm{V}$ & $\mathrm{D}>\mathrm{V}$ & 6 & 0 & - & $+?$ & - \\
\hline $4 c-Y$ & & & $\mathrm{D}>\mathrm{V}$ & $2(3)$ & 0 & - & & \\
\hline $4 a-Y$ & & & $\mathrm{D}>\mathrm{V}$ & 4 & 0 & - & & \\
\hline $5 a-Y$ & 4.47 & $D<V$ & $\mathrm{D}>\mathrm{V}$ & 3 & 1 & - & - & - \\
\hline $7 a-Y$ & 4.72 & $\mathrm{D}=\mathrm{V}$ & $\mathrm{D}>\mathrm{V}$ & 4 & 0 & - & - & - \\
\hline $7 c-Y$ & 4.89 & & & & 0 & - & - & \\
\hline $7 b-Y$ & 4.93 & $?$ & $D>V$ & 1 & 0 & - & - & - \\
\hline$X a-Y$ & & $\mathrm{D}<\mathrm{V}$ & $D>V$ & 2 & 0 & - & & \\
\hline$X b-Y$ & & $\mathrm{D}<\mathrm{V}$ & $\mathrm{D}<\mathrm{V}$ & $2(3)$ & 1 & - & & \\
\hline$X c-Y$ & & $\mathrm{D}<\mathrm{V}$ & $D>V$ & 3 & 1 & - & & \\
\hline $6 a-Y$ & & $\mathrm{D}<\mathrm{V}$ & $\mathrm{D}>\mathrm{V}$ & 3 & 1 & - & & \\
\hline $5 b-Y$ & 5.22 & $\mathrm{D}<\mathrm{V}$ & $\mathrm{D}>\mathrm{V}$ & 3 & 1 & - & - & - \\
\hline$X d-Y$ & & $\mathrm{D}<\mathrm{V}$ & $\mathrm{D}<\mathrm{V}$ & 2 & 1 & - & & \\
\hline $6 c-Y$ & & $\mathrm{D}<\mathrm{V}$ & $\mathrm{D}<\mathrm{V}$ & 1 & 0 & - & & \\
\hline$X e-Y$ & & $\mathrm{D}<\mathrm{V}$ & $\mathrm{D}>\mathrm{V}$ & 1 & 0 & - & & \\
\hline $6 b-Y$ & & $\mathrm{D}<\mathrm{V}$ & $D>V$ & 2 & 0 & - & & \\
\hline \multicolumn{9}{|c|}{ Gadus morhua } \\
\hline$X f-Y^{3}$ & 3.00 & $\mathrm{D}=\mathrm{V}$ & $\mathrm{D}=\mathrm{V}$ & 2 & 0 & - & & - \\
\hline$X g-Y^{2}$ & 4.00 & $D=V$ & $D<V$ & 2 & $1 ?$ & - & + & - \\
\hline $\mathrm{Xh}^{4}$ & 4.50 & $\mathrm{D}=\mathrm{V}$ & $\mathrm{D}=\mathrm{V}$ & 2 & 0 & - & + & + \\
\hline$X i^{3}$ & 5.00 & & & 2 & 0 & V & + & + \\
\hline$X j^{3}$ & 6.00 & & & 2 & 0 & V & + & + \\
\hline $8 a$ & 6.28 & & & 4 & 0 & $\mathrm{D}, \mathrm{V}$ & + & + \\
\hline $8 b$ & 7.94 & & & 2 & 0 & $D, V$ & + & + \\
\hline $\mathrm{Xk}^{3}$ & 8.00 & & & 3 & 0 & $D, V$ & + & + \\
\hline 9 & 11.78 & & & & & $D, V$ & + & + \\
\hline$X I^{3}$ & 12.50 & & & 1 & 0 & $\mathrm{D}, \mathrm{V}$ & + & + \\
\hline \multicolumn{9}{|c|}{ Boreogadus saida } \\
\hline $10 b-Y$ & 5.90 & $\mathrm{D}>\mathrm{V}$ & $\mathrm{D}>\mathrm{V}$ & 0 & 0 & - & + & - \\
\hline$X m-Y^{1}$ & 6.30 & $\mathrm{D}>\mathrm{V}$ & $D>V$ & 0 & 1 & - & + & - \\
\hline$X n^{3}$ & 6.50 & & & 0 & 2 & $\mathrm{D}$ & + & - \\
\hline $10 a-Y$ & 6.60 & $D>V$ & $D>V$ & 0 & 0 & - & + & - \\
\hline $\mathrm{Xo}^{1}$ & 7.30 & & & 0 & 0 & $\mathrm{D}$ & + & + \\
\hline$X p^{3}$ & 8.00 & & & 1 & 2 & $\mathrm{D}$ & + & - \\
\hline $\mathrm{Xq}^{1}$ & 10.10 & & & 0 & 0 & $D, V$ & + & + \\
\hline$X r^{3}$ & 11.00 & & & 0 & 0 & $\mathrm{D}, \mathrm{V}$ & + & + \\
\hline \multicolumn{9}{|c|}{ Arctogadus borisovi } \\
\hline$X s^{5}$ & $<11.90$ & & & 0 & 0 & $\mathrm{D}, \mathrm{V}$ & + & + \\
\hline$X t^{5}$ & 11.90 & & & 0 & 0 & $D, V$ & + & + \\
\hline
\end{tabular}

${ }_{1}^{1}=$ Dunn and Vinter, 1984; ${ }^{2}=$ M'Intosh and Masterman, 1897; ${ }^{3}=$ Russell, 1976; ${ }^{4}=$ Schmidt, 1905; ${ }^{5}=$ Zviagina, 1961. 


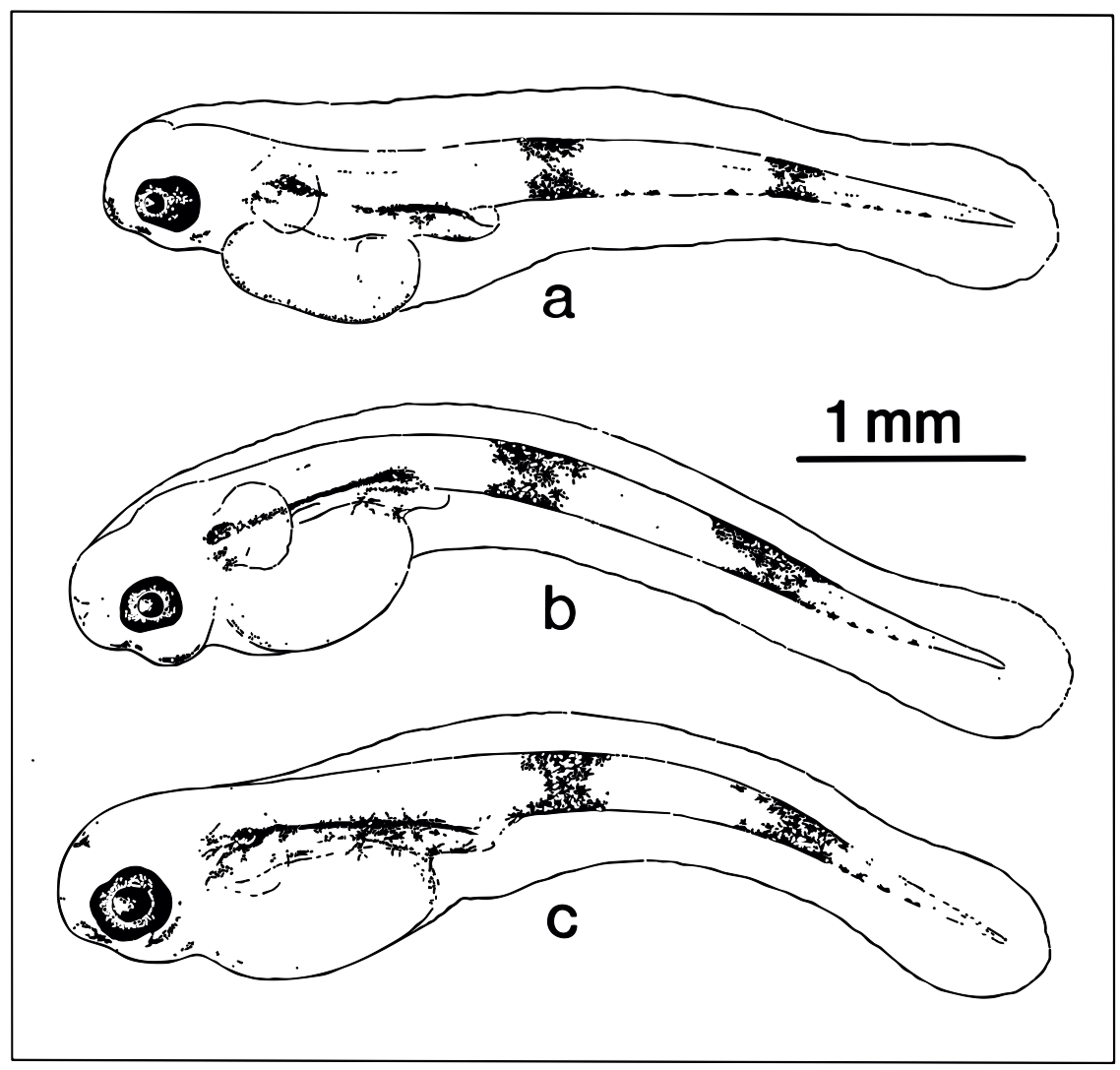

Fig. 3. Reared larvae of Gadus ogac recently hatched from eggs fertilized 17 March 1959, fixed 35 (a and $\mathbf{b}$ ) and 36 (c) days, respectively, after fertilization and measuring $4.01 \mathrm{~mm}, 4.32 \mathrm{~mm}$ and $4.35 \mathrm{~mm} \mathrm{NL}$, respectively (illustrated by P. H. Winther).

ral fin and almost to the caudal tip. There is no caudal finfold. In the other embryo (b) the occipital region is unpigmented, and through the yolk can be seen distinct melanophores of what may be two lateral pigment patches or possibly anterior and posterior internal pigmentation of the dorsal body cavity wall as seen in the larva (Fig. 3a). The embryo has a caudal finfold, and a row of four ventral caudal melanophores is distinctly separate from a second post-anal pigment band, anterior to which distinct melanophores may constitute the dorsal part of a first band. The eyes of both embryos are only faintly pigmented and the lenses are visible.

Neither of the two 32 days old embryos (c and d) have occipital pigmentation. In c internal pigmentation can be seen above the intestine just behind the pectoral fin, and the first post-anal pigment band is visible. In d two post-anal pigment bands can be seen, while the tip of the tail is hidden. Both larvae have attained the characteristic larval pigmentation of the eyes which are circular.
Of five larvae which were recently hatched when sampled 35 days after fertilization on 17 March 1959, two are shown in Fig. $3 a$ and $b$ and the tails of the other three are shown in Fig. 4. A larva of the same batch sampled 36 days after fertilization is shown in Fig. $3 \mathrm{c}$.

The only external pigmentation anterior to the anus in these larvae is located antero-ventrally on the head and below the eyes, except in Fig. 3c, where also a single medial antero-dorsal melanophore is found. There is no occipital pigmentation and no ventral abdominal pigmentation. Internal pigmentation is found dorsally on the body cavity wall and on the gut including one or two melanophores ventrally behind the yolk. The eyes are semi-oval (Fig. 3b) or they have a slight dorsoventral constriction (Fig. $3 a$ and $c$ ). The eye of the oldest of the three larvae (Fig. 3c) is as large as that of the largest $G$. ogac larva available for this study (Fig. 5b) with a lens which is exceptionally large even compared to this older larva. 


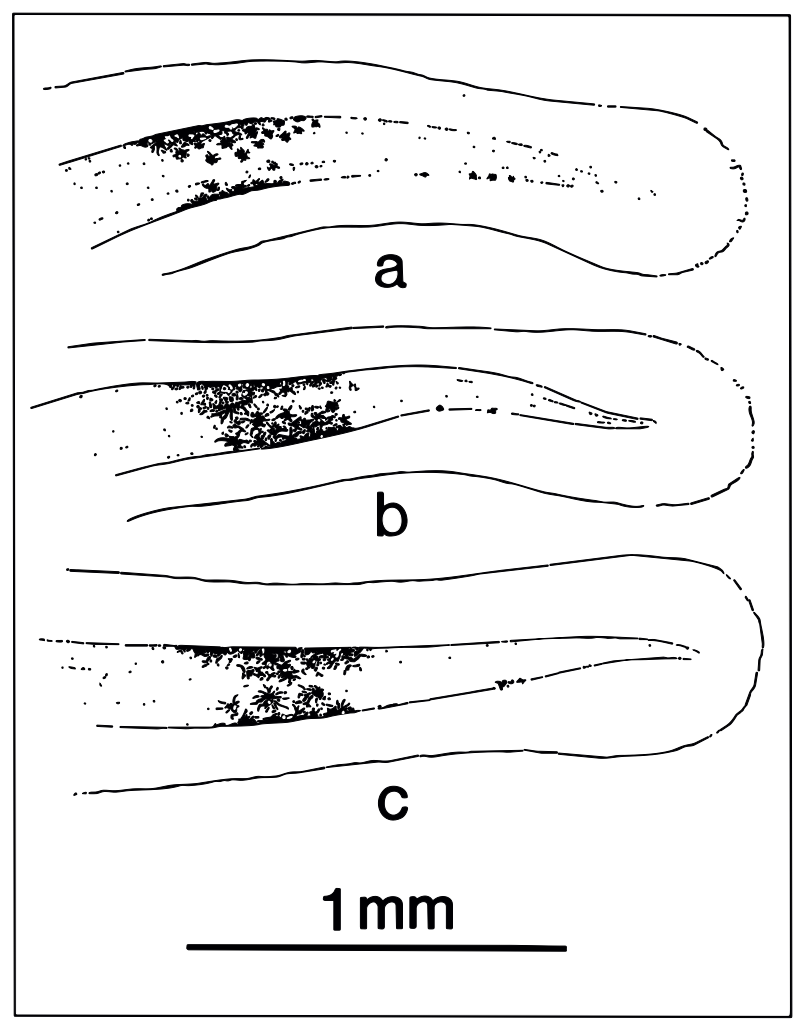

Fig. 4. Tails of reared Gadus ogac larvae fertilized 17 March 1959 and fixed 35 days after fertilization (illustrated by P. H. Winther.).

Morphometric measurements and pigmentation characteristics for larvae of G. ogac, G. morhua, $B$. saida and $A$. borisovi are presented in Tables 1 and 2 , respectively.

The three larvae in Fig. 3 have two complete post-anal pigment bands with most of the pigment in each concentrated dorsally and ventrally. In Fig. $4 \mathrm{a}$, the second pigment band has split into dorsal and ventral bars. In the six fish illustrated in Fig. 3 and 4 the dorsal part of the first post-anal pigment band is slightly wider than, equal to or slightly narrower than the ventral part, whereas in the second band the dorsal part is usually longer than or (in one of the six larvae) equal in length to the ventral part. The bands are separated in c. by one to three times the width of the dorsal part of the first band. There are 2-4 medio-ventral caudal melanophores close to (Fig. $3 a-c$ ) or well separated from (Fig. $4 a-c)$ the second band, but no medio-dorsal ones. The smallest larva (Fig. 3a) has three medio-ventral melanophores between the post-anal pigment bands and its pigment bands are narrower than in the other larvae. This larva also has less internal pigmentation with a break in the dorsal pigmentation of the body cavity wall, and it seems in poorer condition with less yolk and a smaller head than the other two.

Gadus ogac larvae reared in 1960 and drawn when pigments had deteriorated somewhat (Fig. 5 and 6)

Ten yolk sac larvae, of which two are shown in Fig. 5 and three tails in Fig. 6, were sampled 8 days after hatching and 35 days after having been fertilized on 14 March 1960. None of these larvae appear to have reached the feeding stage, since there is still yolk present, and the intestine is short and straight and does not seem to open externally. Also, the mouth is still located below the eyes, keeping the $\mathrm{B} / \mathrm{A}$ ratio high and the $\mathrm{C} / \mathrm{A}$ ratio low. The tail looks stunted in Fig. 5 a which has the smallest E/A ratio of 0.16 , while its $B / A$ ratio of 0.59 is similar to that of the other larvae of a similar size. The eyes are slightly ovoid with a choroid fissure.

These larvae have neither occipital nor ventral abdominal pigmentation. The only external pigmentation anterior to the anus can be seen on the snout just above the upper jaw and along the lower jaw (the latter, perhaps, is not pigment). The dorsal wall of the body cavity is pigmented, most intensely anteriorly and posteriorly, and slight pigmentation extends to the ventral surface of the intestine posteriorly. In Fig. 5a, a small pigment spot can be seen on the anterior end of the yolk sac. The two post-anal pigment bands are far apart and are split up into dorsal and ventral bars. The dorsal bar of the first pair is slightly shorter than the ventral one, whereas in the second pair the dorsal bar is usually longer than, but in some larvae slightly shorter than the ventral one. There are $0-1$ medio-dorsal and 1-3 medio-ventral caudal melanophores. The dorsal caudal melanophore found in 6 of the 10 larvae is either located on the tail as in Fig. 6a or adjacent to it in the finfold as in Fig. 5b. In Fig. 5a, a melanophore is found postero-dorsally in the finfold. Three larvae have some pigment between the dorsal and ventral bars as in Fig. 6a and c.

Gadus ogac larvae caught in 1973-74 and drawn in 1977 when pigments had deteriorated somewhat (Fig. 7)

Three wild-caught yolk sac larvae from Disko Bay and Disko Fjord (Fig. 7a-c) similar in size to the largest of the reared $G$. ogac larvae are referred to this species on the basis of the total absence of pre-anal external pigment; there is neither occipital nor ventral abdominal pigment, a similar B/A ratio of 0.59 and a C/A ratio of 0.16 . These larvae have reached a slightly more advanced stage of development being slimmer, with almost no yolk and with the mouth in a more terminal position. However, they still have no discernible stomach, and the intestine is short and straight and does not 


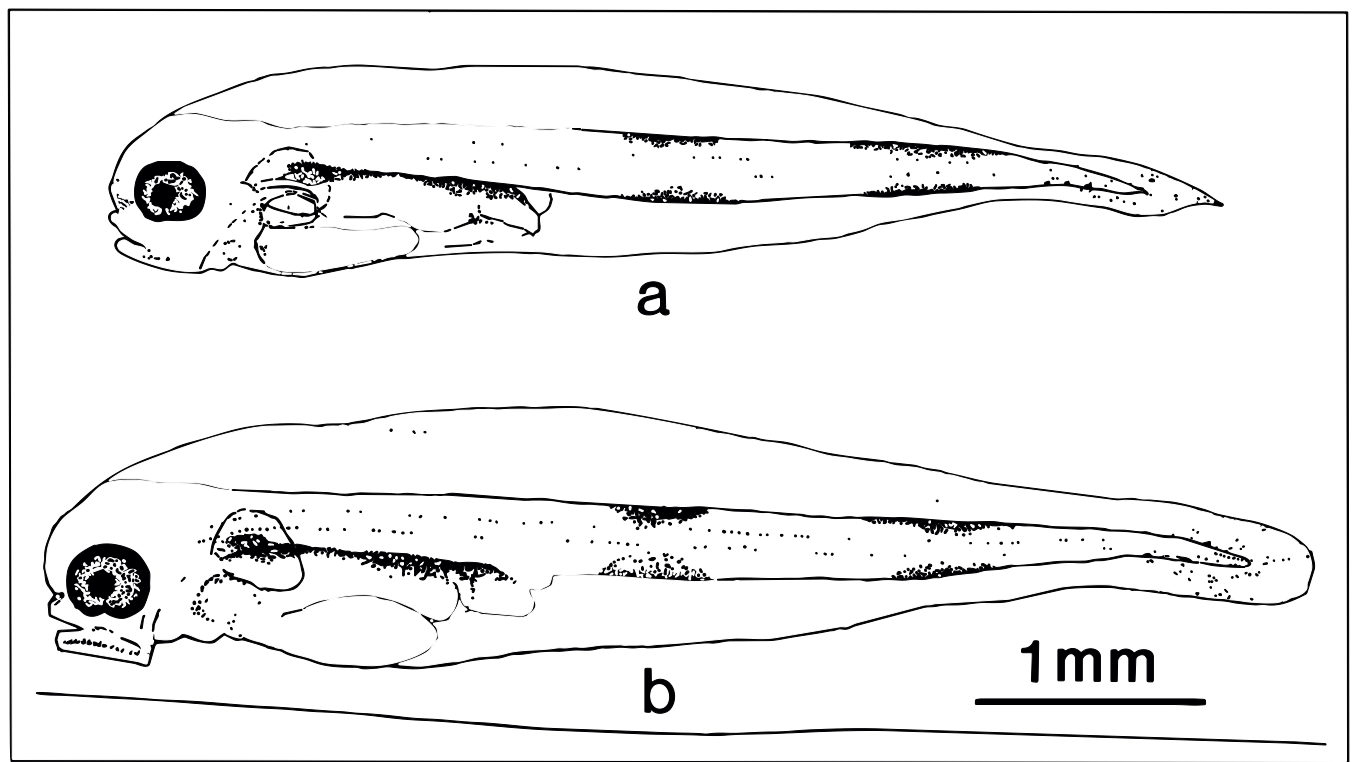

Fig. 5. Reared 8 days old larvae of Gadus ogac from eggs fertilized 14 March and hatched on 10 April 1960, measuring $4.47 \mathrm{~mm} \mathrm{NL} \mathrm{(a)} \mathrm{and} 5.22 \mathrm{~mm} \mathrm{NL}$ (b) (illustrated by J. Kreutzmann).

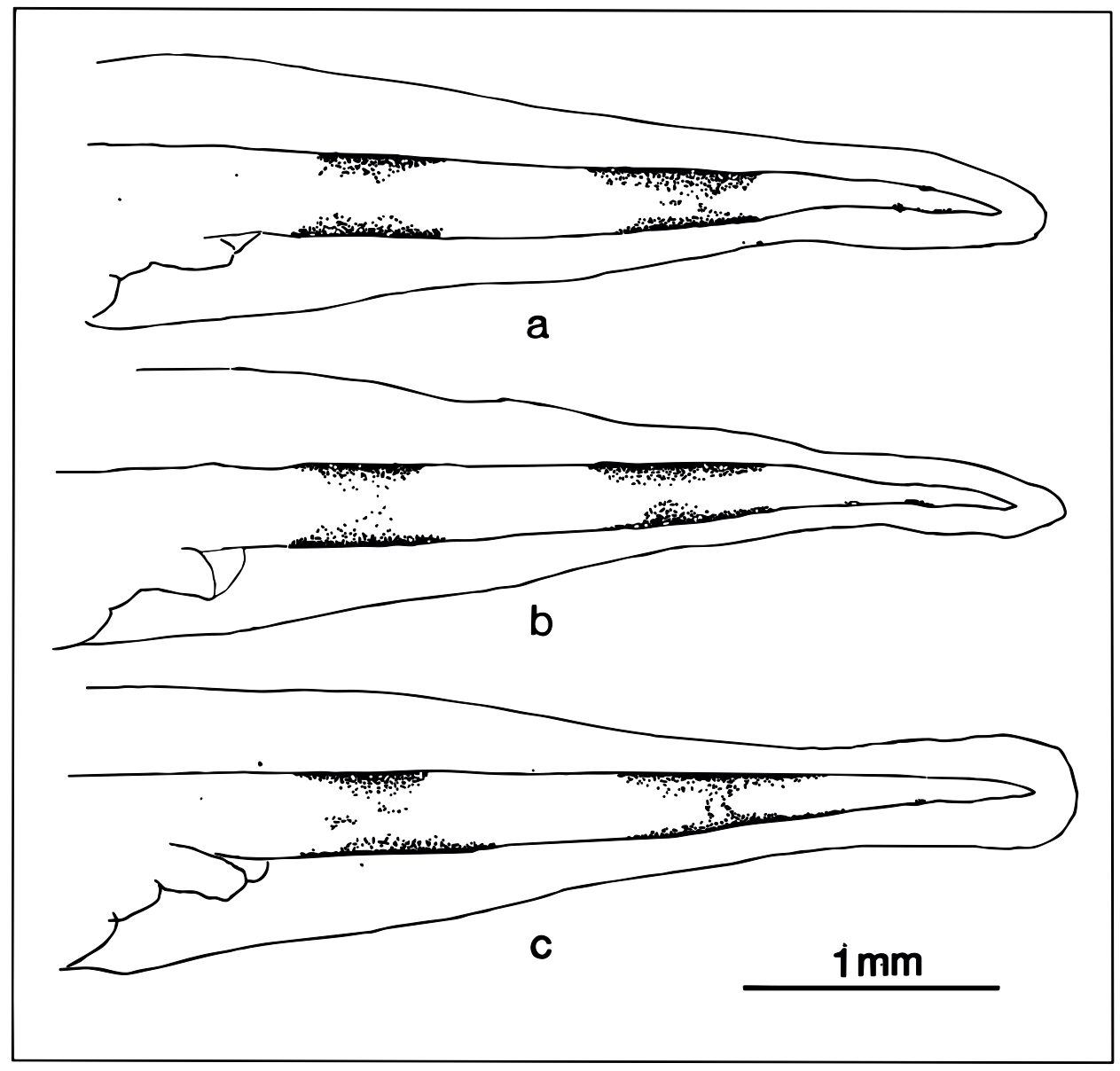

Fig. 6. Tails of reared Gadus ogac larvae fertilized 14 March and hatched 10 April 1960 (illustrated by J. Kreutzmann). 


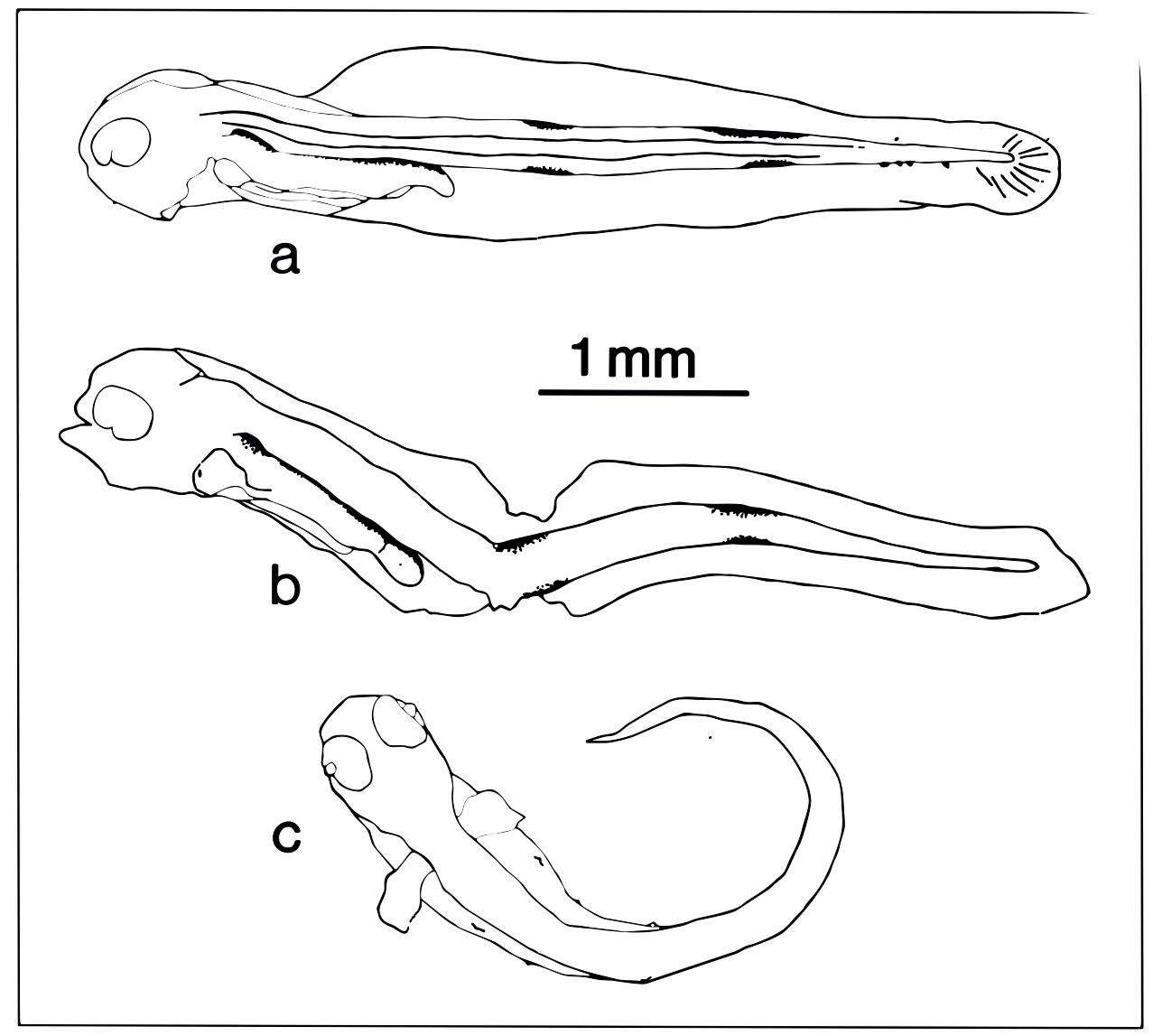

Fig. 7. Planktonic Gadus ogac larvae caught (a) on 7 June 1973 and (b and c) on 17 June 1974 at Disko, West Greenland, and measuring $4.72 \mathrm{~mm}, 4.93 \mathrm{~mm}$ and $4.89 \mathrm{~mm}$ $\mathrm{NL}$, respectively. The pigmentation of the eyes is not shown, and in (c) no pigments are shown (illustrated by O. G. N. Andersen).

seem to open externally. The dorsal pigmentation of the body cavity wall is distinctly most intense anteriorly and posteriorly, and in between it consists of two narrow dorso-lateral pigment lines placed close together (not apparent in lateral view). Figure $7 \mathrm{~b}$ has a small faded pigment spot located antero-laterally on what has been interpreted as the cardium, but perhaps it is analogous to the pigment spot found on the yolk sac in Fig. $5 a$, since the position within the body profile is the same. The eyes are slightly ovoid with a choroid fissure and they are so heavily pigmented (not shown) as to obscure the lenses in transmitted light. Only when viewed from above as in Fig. 7c, the lenses can be seen. Figure $7 c$ also shows most clearly the position of the pectoral fins as well as three pairs of lateral organs.

The post-anal pigment bars are similar to and spaced like those in Fig. 5 and 6, although they are slightly shorter, but there are no medio-dorsal caudal melanophores. The medio-ventral caudal melanophores, numbering four and one in Fig. 7a and $7 \mathrm{~b}$, respectively, much resemble those in Fig. 5 and 6 , but in Fig. 7a the melanophores are situated more or less in the finfold, and the single caudal melanophore in Fig. $7 \mathrm{~b}$ is near the tip of the tail, giving a large $F$ value (Table 1 ).

\section{Gadus morhua larvae caught in 1957 and drawn} when pigments were fully intact (Fig. 8)

Two larvae, $6.3 \mathrm{~mm}$ and $7.9 \mathrm{~mm}$ long, caught off Godthåb/Nuuk (Fig. $8 a$ and b) are referred to G. morhua due to the extensive pre-anal pigmentation, especially dorsally in the occipital region and on the nape, ventrally on the isthmus and abdomen and ventro-laterally on the thorax. In Fig. $8 \mathrm{~b}$, a short medio-dorsal pigment stripe is found dorsally above the intestinal loop between the pigmentation of the nape and the first post-anal dorsal pigmentation. Pigment can also be found anterior to the base of the pectoral fin (Fig. 8a) and on the operculum (Fig. 8b). Also, the snout and both jaws are slightly pigmented. The post-anal pigment 


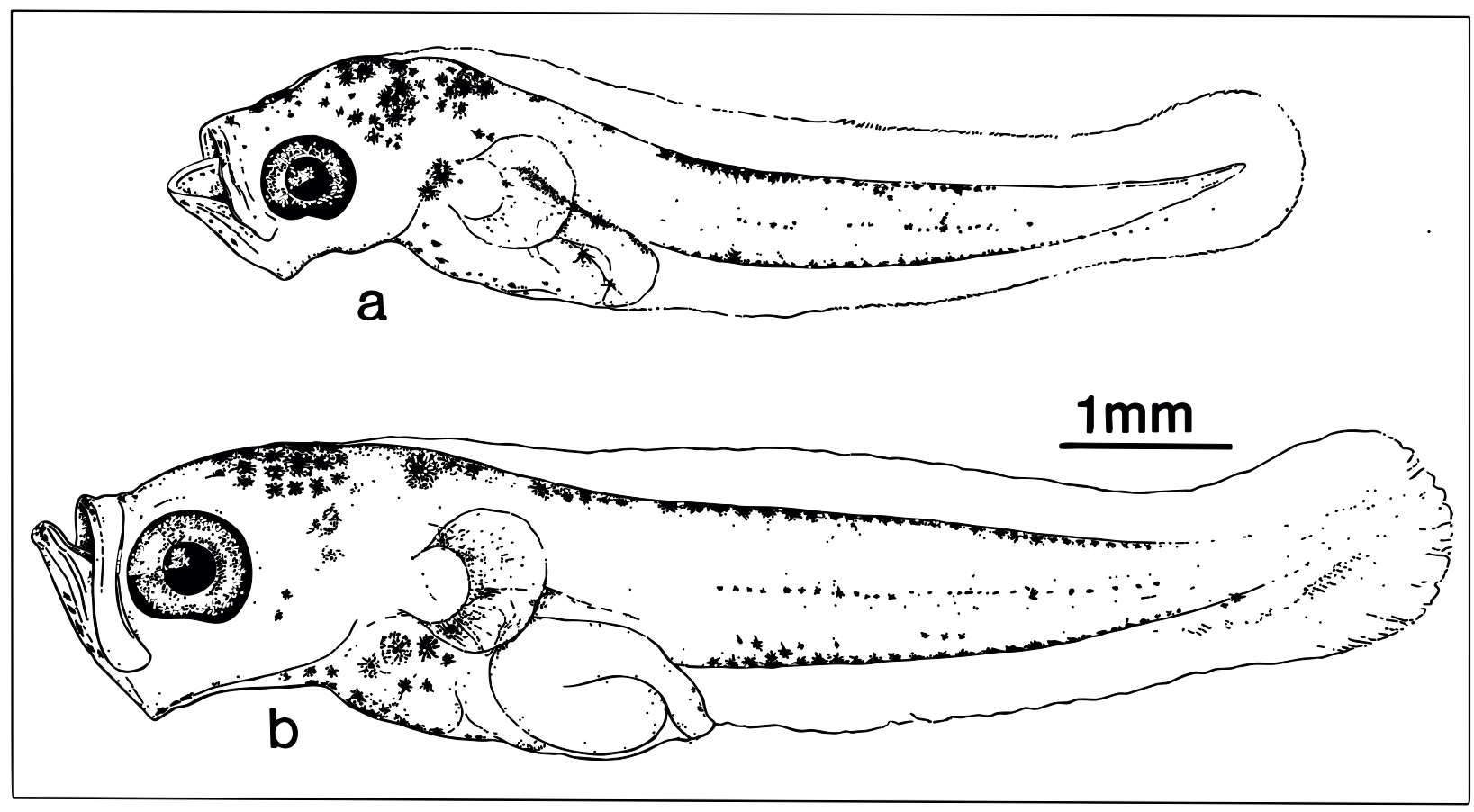

Fig. 8. Planktonic Gadus morhua larvae caught on 17 June 1957 in the coastal area off Godthåb/Nuuk, West Greenland, and measuring $6.28 \mathrm{~mm}(\mathbf{a})$ and $7.94 \mathrm{~mm} \mathrm{NL}$ (b) (illustrated P. H. Winther).

bars have fused into single long and narrow mediodorsal and medio-ventral pigment stripes not continuous to the occipitum in Fig. 8a, but nearly so in Fig. 8b. These stripes are likely paired, one pair dorsally on each side of the midline and the same ventrally (L. Van Guelpen, Huntsman Marine Science Centre, New Brunswick, pers. comm.). A few melanophores are found ventro-laterally on the tail, and mid-laterally there is a more or less complete line of melanophores. The larvae have two and four medio-ventral caudal melanophores separated from the ventral stripe and located more or less in the finfold. The internal pigmentation is somewhat obscured by the pectoral fin in Fig. $8 b$ but can be seen covering the upper wall of the body cavity in Fig. 8a. The mouth is more developed and more superior in position compared to the oldest of the reared larvae and the wild-caught larvae of G. ogac from the Disko area. Both G. morhua larvae lack yolk, their intestinal tract has developed a loop, and presumably they both have an external anus opening laterally at the base of the finfold.

Gadus morhua post-larva caught in 1959 and drawn in 1962 when pigments seemed quite intact (Fig. 9)

An $11.8 \mathrm{~mm}$ larva caught south of Godthåb is referred to $G$. morhua on the basis of extensive external pre-anal pigmentation, although the nape pigment in Fig $8 \mathrm{~b}$ is absent here, and the pigment above the pectoral fin is faint. Pigmentation has spread over the body, and all fins are beginning to appear.
Boreogadus saida caught on 15 May 1973 and sketched immediately after fixation and drawn again in more detail in 1977 when pigments had deteriorated to a large extent (Fig. 10a and 10b)

In a late $B$. saida yolk sac larva from the Disko area the mouth was formed, although it was still located below the eye. Also, some yolk was still present and the gut was uncoiled. The dorsal finfold extended to the snout. When the larva was drawn soon after fixation (Fig. 10a), the pre-anal external pigmentation consisted of clearly distinguishable melanophores on the occipitum and on the nape and just behind it, whereas none were found on the ventral abdomen. Melanophores were also found on the upper wall of the body cavity. There were two about equally long dorsal and two shorter ventral caudal bands, the first one about $1 / 4$ and the second one about $3 / 4$ as long as the dorsal stripe. The eye was pigmented and had a choroid fissure.

When the larva was drawn again 4 years later major changes had occurred in pigmentation and size (Fig. 10b). Only faint tinges of pigmentation remained where the melanophores had been before, and the dorsal pigmentation immediately behind the nape had disappeared completely. Furthermore, the larva had shrunk about $10 \%$ in length. About $70 \%$ of this reduction was due to a $40 \%$ shrinkage of the tail posterior to the second pair of pigment bars ( $E$ in Fig. 1). In the upper jaw is a row of teeth so minute, that they can only be seen in the illustration with a magnifying glass. 


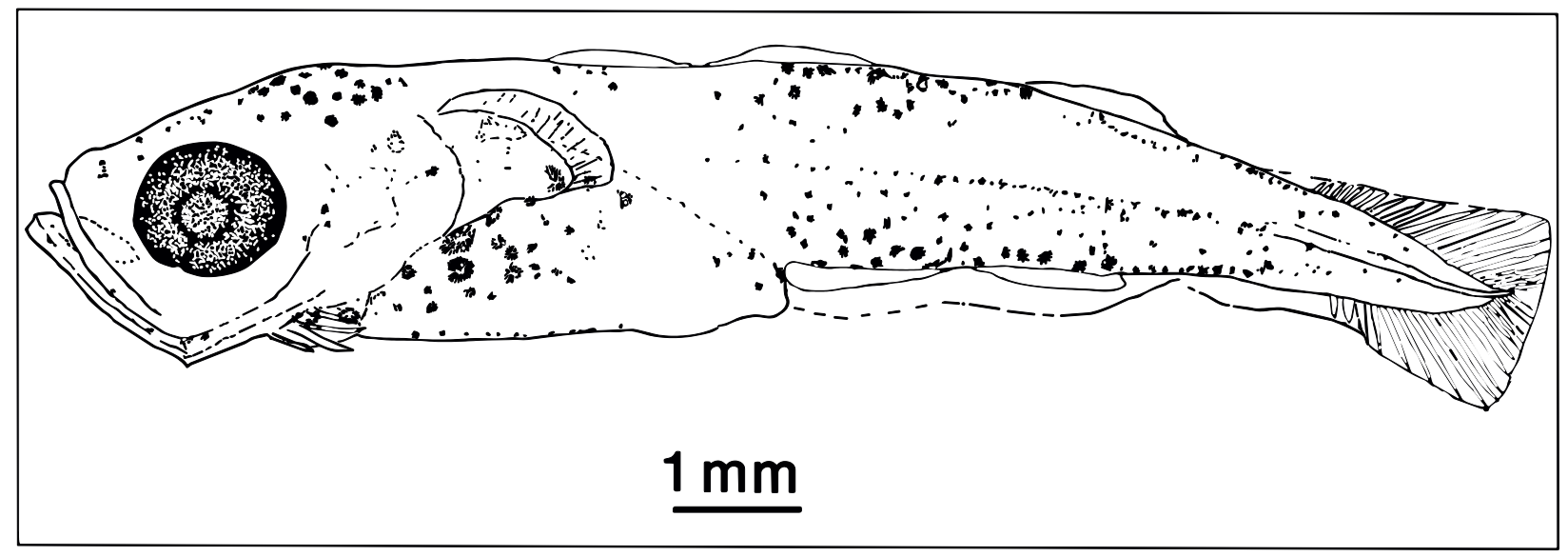

Fig. 9. Planktonic Gadus morhua larva caught on 11 July 1959 south of Godthåb/Nuuk, West Greenland, and drawn in 1962 measuring 11.78 mm NL (illustrated by J. Kreutzmann).

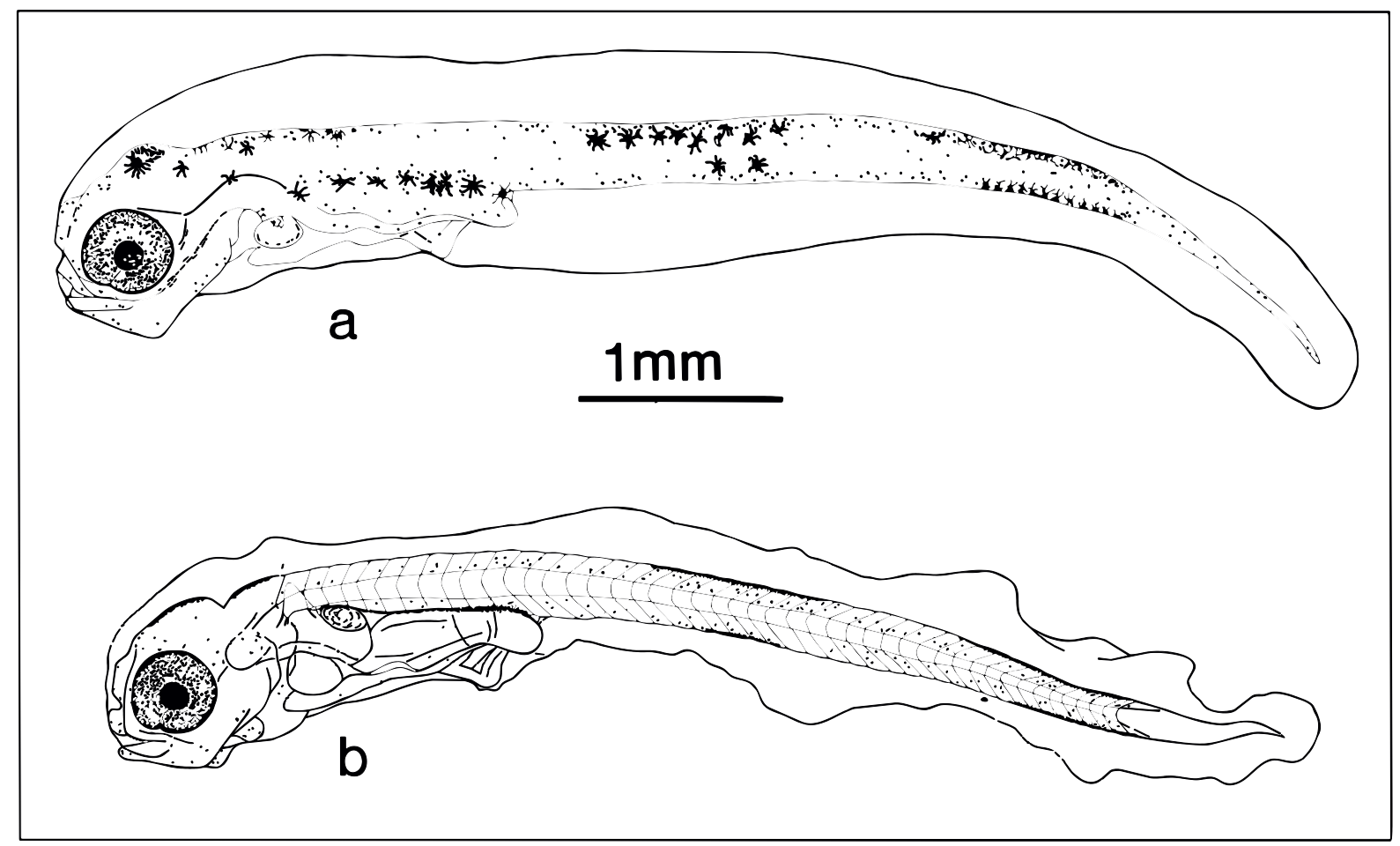

Fig. 10. Planktonic Boreogadus saida yolk sac larva caught on 15 May 1973 at Disko, West Greenland and drawn (a) in 1973 and (b) in 1977 measuring $6.30 \mathrm{~mm}$ and $5.90 \mathrm{~mm} \mathrm{NL}$, respectively (illustrated by O. G. N. Andersen).

\section{Discussion}

It is no longer possible to compare the pigmentation in the illustrated eggs and larvae with pigmentation in eggs and larvae from the 1925-85 plankton surveys in West Greenland waters, since the pigments have disappeared from all of the larvae in question. Therefore, only the drawings of eggs and yolk sac larvae of G. ogac in Fig. 2 to 7 can be used to compare pigmentation, and the only materials available on $G$. morhua and B. saida from West Greenland are the drawings of late larvae in Fig. 8 and 9 and the yolk sac larva in Fig. 10, respectively. 
The 1.13 to $1.17 \mathrm{~mm}$ diameter eggs of $\mathrm{G}$. ogac (Fig. 2) are smaller than those of G. morhua reported by Russell (1976) to be from 1.16 to 1.89 $\mathrm{mm}$, by Fahay (1983) to be from 1.2 to $1.6 \mathrm{~mm}$ and by Hansen (1968) to average 1.40 to $1.44 \mathrm{~mm}$ in Canadian waters. Otherwise the early stages are very similar. Before hatching, embryos of both species assume the larval pigment pattern. Ventral caudal melanophores at the tip of the tail number 1 to 2 in G. morhua and 4 to possibly 5 in G. ogac. Only G. morhua embryos at this stage of development have pre-anal external dorsal pigmentation, especially in the occipital region (Apstein, 1909; Russell, 1976; Fahay, 1983), where G. ogac has none (Fig. 2b-d).

The eggs of $B$. saida are larger (1.53 to 1.90 $\mathrm{mm}$ ) than those of $\mathrm{G}$. ogac and pigmentation of the embryo appears late in development, but finally assumes the characteristic larval pigmentation with two post-anal pigment bands (Russell, 1976). Like in G. ogac embryos, B. saida embryos have virtually no pre-anal pigmentation other than dorsally on the body cavity wall (L. Van Guelpen, Huntsman Marine Science Centre, New Brunswick, pers. comm.). Eyes are pigmented. L. Van Guelpen (pers. comm.) found one dorsal melanophore at the caudal tip in 1 out of 4 late stage embryos examined.

The post-anal pigmentation of the reared $G$. ogac larvae is rather similar to that of G. morhua larvae. Of the characteristic post-anal "gadid" pigment bands (Schmidt, 1905; Fahay, 1983) both species have the two anterior ones complete, in older yolk sac larvae separating into dorsal and ventral bars. In G. morhua, however, both of the dorsal bars (or parts) are usually shorter than or equal in length to the ventral ones, whereas in $G$. ogac, the first dorsal bar (or part) is shorter than, equal to or longer than the ventral one in 11, 2 and 1 out of 14 larvae respectively, while in the second pair the numerical sequence is the reverse, 2, 1 and 15 in 18 larvae. In all of the $G$. ogac larvae, the largest of which is about $5.4 \mathrm{~mm}$ (presuming a $B / A$ ratio of 0.59 (Table 1)), the two dorsal, and ventral, pigment bars are still far apart, whereas in G. morhua the ventral bars are fused at a length of $5.0 \mathrm{~mm}$ and the dorsal bars at $6.3 \mathrm{~mm}$ (Table 2).

The number of medio-ventral caudal melanophores in G. morhua yolk sac larvae is 1 or 2, (Table 1 and L. Van Guelpen pers. comm.) well separated from the second ventral pigment bar, and it is 1 to 6 in G. ogac, where the melanophores can be continuous with the second bar in the youngest larvae. Russell (1976) shows one medio-dorsal caudal melanophore in a newly hatched $4 \mathrm{~mm} \mathrm{NL}$ larva of $G$. morhua, but not in a preserved $3 \mathrm{~mm} \mathrm{NL}$ yolk sac larva, which has shrunk. Nor is such a melanophore found in a $4.5 \mathrm{~mm} \mathrm{NL}$ late larva, in which the yolk has been resorbed, pictured by Schmidt (1905). In older G. morhua larvae, up to four melanophores are found (Fig. 8a). In G. ogac, a dorsal caudal melanophore is found in six out of ten reared yolk sac larvae sampled eight days after hatching, but not in six younger and smaller reared larvae or in three wild-caught yolk sac larvae of the same size as the eight days old larvae. Also the internal pigmentation on the upper wall of the body cavity in $G$. ogac is very similar to that of G. morhua (Schmidt, 1905; Murray and Hjort, 1912; Russell, 1976), although a break in this pigmentation seems to be the exception rather than the rule as in G. morhua. Thus, it can be quite difficult to distinguish the yolk sac larvae of these two species from one another on the basis of external postanal and internal pigmentation alone.

Like in the late stage embryos, the yolk sac larvae of G. ogac lack pre-anal dorsal external pigmentation, whereas in all larval stages of $G$. morhua such pigmentation is well developed, especially in the occipital region and commonly on the nape and also mid-ventrally on the abdomen (Ehrenbaum, 1905-09; Schmidt, 1905; Murray and Hjort, 1912; Russell, 1976; Fahay, 1983). Apart from an anterodorsal melanophore on the head in one larva, three recently hatched yolk sac larvae of $G$. ogac have only slight pre-anal external pigmentation which is located ventro-laterally around the eyes (Fig. 3) and may correspond to what seems to be a meager pigmentation on the snout and on the lower jaw in the older reared larvae (Fig. 5).

Gadus ogac larvae up to $5.2 \mathrm{~mm}$ NL still have yolk, whereas in the $4.5 \mathrm{~mm} \mathrm{NL} \mathrm{G.} \mathrm{morhua} \mathrm{larvae}$ examined the yolk has been resorbed. Gadus ogac larvae have shorter heads and longer tails than those of G. morhua. The C/A ratio (Table 1) in 4.0$5.2 \mathrm{~mm} \mathrm{NL} \mathrm{G.} \mathrm{ogac} \mathrm{larvae} \mathrm{is} 0.13-0.16$, whereas in G. morhua larvae it is 0.14 at $4.0 \mathrm{~mm} \mathrm{NL}$ and 0.21 and 0.20 in 4.5 and $5.0 \mathrm{~mm} \mathrm{NL}$ larvae, respectively. The corresponding B/A ratios are higher (0.550.59 ) in the same G. ogac larvae compared to 0.500.55 in the $G$. morhua larvae and the smaller $G$. morhua yolk sac larvae.

Most likely it will be possible to distinguish more advanced $G$. ogac larvae from those of $G$. morhua on the basis of pre-anal external pigmentation. In older larvae of G. morhua, external pigmentation is extensive in the occipital region and nape, and pigmentation is also to be found mid-ventrally on the abdomen, on the operculum and at the base of the pectoral fins.

In G. morhua larvae from West Greenland Waters (Fig. 8 and 9 and referred to in Table 1) meas- 
uring $6.3-11.8 \mathrm{~mm} \mathrm{NL}$, the $\mathrm{C} / \mathrm{A}$ ratios of $0.24-0.26$ are similar to the ratios of $0.24-0.27$ in $6.0-12.5 \mathrm{~mm}$ $\mathrm{NL}$ larvae of $G$. morhua from boreal waters south of Greenland (Xj-XI in Table 1). The West Greenland larvae have comparatively larger eyes, and the difference in horizontal eye width (O in Fig. 1) increases with NL ( $A$ in Fig 1 ) from being $24 \%$ greater at $A=6.3 \mathrm{~mm}$ to being $38 \%$ greater at $A=11.8 \mathrm{~mm}$ (from Fig. 11). In larvae from both locations there is a slight increase with $A$ in $O$ relative to $A(O / A)$, and more so in the West Greenland larvae. This ratio is $26 \%$ greater in the West Greenland larvae at $A=$ $6.3 \mathrm{~mm}$ and $37 \%$ greater at $A=11.8 \mathrm{~mm}$ (Fig. 11).

Yolk sac larvae of $B$. saida differ from the Gadus species by having no ventral abdominal pigmentation, both dorsal post-anal pigment bars being wider than the ventral ones, the second pair of bars being wider than the first pair and by having 0 to 2 dorsal melanophores at the caudal tip and usually 0 , but sometimes 1 ventral one. Also the B/A ratio is 0.63-0.65 compared to no more than 0.59 in $G$. ogac and 0.51 in G. morhua, and the dorsal finfold extends to the snout, whereas in the other species it is not found anterior to the eye. Boreogadus saida yolk sac larvae have occipital pigmentation like $G$.

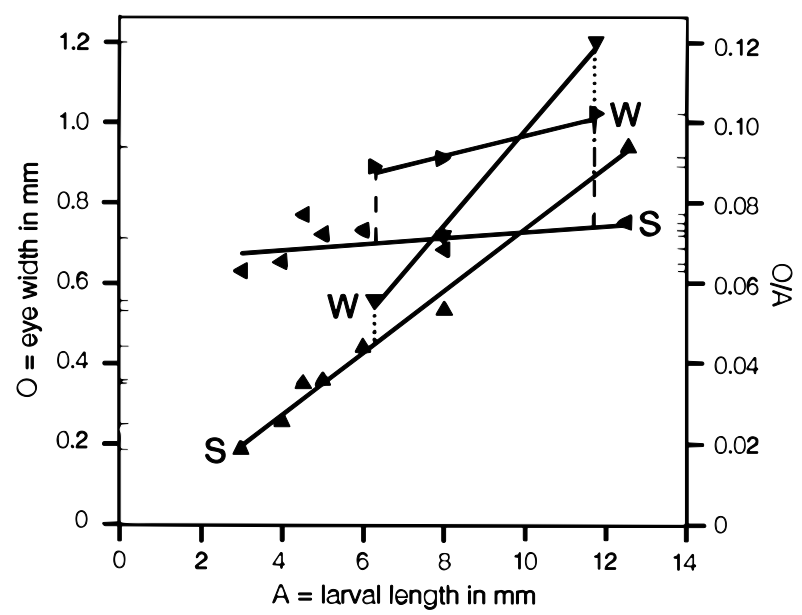

Fig. 11. Correlation of horizontal eye width $(O)$ and eye width/NL ratio (O/A) to NL $(A)$ in the $G$. morhua larvae listed in Table 1, from West Greenland (W, $\boldsymbol{\nabla}$ and in the figure) and from southern waters (S, $\boldsymbol{\Delta}$ and in the figure). For the West Greenland larvae ( $8 a-9$ in Table 1), the correlation of $\mathrm{O}$ to $\mathrm{A}$ (shown as $\boldsymbol{\nabla}$ ) is $\mathrm{O}=\mathrm{A} \times 0.1179-0.1949$ with $R^{2}=0.997$ and the correlation of O/A to $A$ (shown as ) is $\mathrm{O} / \mathrm{A}=\mathrm{A} \times 0.00245+0.0728$ with $R^{2}=0.976$. Similarly for larvae of southern origin $(X j-X I$ in Table 1), the correlation of $O$ to $A$ (shown as $\boldsymbol{\Delta}$ ) is $\mathrm{O}=\mathrm{A} \times 0.0766-0.0304$ with $\mathrm{R}^{2}$ $=0.990$ and the correlation of $\mathrm{O} / \mathrm{A}$ to $\mathrm{A}$ (shown as ) is $O / A=A \times 0.00075+0.0658$ with $R^{2}=$ $0.212 . R^{2}=$ coefficient of determination. morhua. The yolk is absorbed between 6.6 and 7.3 $\mathrm{mm} \mathrm{NL}$ compared to 4.0 and $4.5 \mathrm{~mm}$ in G. morhua (Table 1). The dorsal pigment bars are the first to fuse between 6.3 and $7.3 \mathrm{~mm} \mathrm{NL}$ followed by the ventral ones at 10-11 $\mathrm{mm} \mathrm{NL}$, while in G. morhua, the ventral bars are fused by $5.00 \mathrm{~mm} \mathrm{NL}$ and the dorsal bars at approximately $6.3 \mathrm{~mm}$ (Table 2).

Larvae of $A$. borisovi pictured by Zviagina (1961) are heavily pigmented pre-anally, particular in the occipital region and laterally on the abdomen, which clearly distinguish them from G. ogac, and less so from G. morhua, where abdominal pigments are also found mid-ventrally.

\section{Acknowledgements}

We thank Sv. Aa. Horsted, former director of the Greenland Fisheries Research Institute, Copenhagen and J. G. Nielsen and Bent J. Muus at the Zoological Museum, University of Copenhagen for helpful advice and criticism and L. Van Guelpen, Atlantic Reference Centre, Huntsman Marine Science Centre, St. Andrews, New Brunswick for a very thorough review of the manuscript.

\section{References}

ANDERSEN, O. G. N. 1981. The annual cycle of phytoplankton primary production and hydrography in the Disko Bugt area, West Greenland. Meddr. Grønl. Biosci,. 6: $65 \mathrm{p}$.

APSTEIN, C. 1909. Die Bestimmung des Alters pelagisch lebender Fischeier. Mitt. Inst. Seefisch. Hamburg, 25(12): 365-373.

DUNN, J. R., and B. M. VINTER. 1984. Development of larvae of the saffron cod, Eleginus gracialis, with comments on the identification of gadid larvae in Pacific and Arctic waters contiguous to Canada and Alaska. Can. J. Fish. Aquat. Sci., 41(2): 304-318.

EHRENBAUM, E. 1905-1909. Eier und Larven von Fischen. Nordisches Plankton, 1: 413 p. Lipsius and Tischer, Kiel and Leipzig.

FAHAY, M. P. 1983. Guide to the early stages of marine fishes occurring in the western North Atlantic Ocean, Cape Hatteras to the southern Scotian Shelf. J. Northw. Atl. Fish. Sci., 4: 168-179.

HANSEN, P. M. 1949. Studies on the biology of the cod in Greenland waters. ICES Rapp. Proc.-Verb., 123: $1-77$.

1968. Report on cod eggs and larvae. Environmental Surveys - NORWESTLANT 1-3, 1963, part 1 (text and figures). ICNAF Spec. Publ., 7: 127-137.

HUNTER, J. G., S. T. LEACH, D. E. McALLISTER, and M. B. STEIGERWALD. 1984. A distributional atlas of records of the marine fishes of Arctic Canada in the National Museums of Canada and Arctic Biological Station. National Museum of Canada. Syllogeus, 52: $34 \mathrm{p}$.

JENSEN, A. S. 1926. Investigations of the "Dana" in West Greenland waters, 1925. With an appendix (List of the fishes of Greenland). ICES Rapp. Proc.-Verb., 39: 85-102. 
1948. Contributions to the ichthyofauna of Greenland 8-24. Spolia zool. Mus. haun., 9, 182 p. +4 tabs.

JENSEN, A. S., and P. M. HANSEN. 1931. Investigations on the Greenland cod (Gadus callarias L.) with an introduction on the history of the Greenland cod fisheries. ICES Rapp. Proc.-Verb., 72(1): 1-41.

M'INTOSH, W. C., and A. T. MASTERMAN. 1897. The lifehistories of the British marine food-fishes. C. J. Clay, London: 467 p., 45 Text figs., PIs I-XX.

MURRAY, J., and J. HJORT. 1912. The depths of the ocean. Macmillan and Co. Lmt., London: $821 \mathrm{p}$.

NIELSEN, J. G., and J. M. JENSEN. 1967. Revision of the Arctic cod genus Arctogadus (Pisces, Gadidae). Meddr. Grønl., 184(2): 28 p. (+ 1 pl).

NIELSEN, J. R. 1992. Uvakkens biologi Gadus ogac (Richardson). (The biology of Greenland cod, Gadus ogac (Richardson)). Report to the Home Rule, Greenland. Greenland Fisheries Research Institute, Copenhagen ISBN 87-87838-93-1: 119 p. + 5 p. (In Danish) (Summary in Greenlandic).

NIELSEN, J. R., and R. MORIN. 1993. Bibliography of Greenland cod, Gadus ogac Richardson 1780-1992.
Can. Manuscr. Rep. Fish. Aquat. Sci., 2191: III + $28 \mathrm{p}$.

RUSSELL, F. S. 1976. The eggs and the planktonic stages of British marine fishes. Acad. Press, London, New York, San Francisco: 524 p.

SCHMIDT, J. 1905. The pelagic post-larval stages of the Atlantic species of Gadus. Part 1. Meddr. Komn. Dan. Havunders., Ser. Fisk., 1(4): 74 p. (+ 3 pls).

SCOTT, W. B., and M. G. SCOTT. 1988. Atlantic fishes of Canada. Can. Bull. Fish. Aquat. Sci., 219, 731 p.

SMIDT, E. L. B. 1979. Annual cycles of primary production and of zooplankton at Southwest Greenland. Meddr. Grønl., Biosci., 1: 52 p.

SVETOVIDOV, A. N. 1948. Fauna SSSR. Ryby, 9 (4). Treskoobraznye. (Fauna of the U.S.S.R. Fishes, 9, 4 Gadiformes). Zool. Inst. Akad. Nauk SSSR 34. (Translated from Russian by the Israel Prog. for Sci. Transl, Jerusalem, 1962).

ZVIAGINA, O. A. 1961. Data on the propagation and development of fish of Laptev Sea. 1. East-Siberian cod (Arctogadus borisovi, Gadidae). Akad. Nauk SSSR. Tr. Inst., 43: 320-327. (Eng. translation, Fish. Res. Board Can., Transl. Ser. No. 1278). 